\title{
Clearance of Oxidatively Damaged Cells by Macrophages: Recognition of Glycoprotein Clusters by Macrophage-Surface Nucleolin as Early Apoptotic Cells
}

\author{
Yuichi Miki, Takashi Itoh, Kazuya Hirano, Shigetoshi EdA, Akiko HaYashi, \\ Masahiro YAMANAKA, and Masatoshi BePPU* \\ School of Pharmacy, Tokyo University of Pharmacy and Life Sciences; 1432-1 Horinouchi, Hachioji, Tokyo 192-0392, \\ Japan. Received August 25, 2008; accepted January 15, 2009; published online February 3, 2009
}

The mechanism of macrophage recognition of oxidatively damaged cells was investigated. Jurkat $\mathrm{T}$ cells exposed to various concentrations of $\mathrm{H}_{2} \mathrm{O}_{2}$ were bound and phagocytosed by macrophages. The cells exposed to $0.1 \mathrm{mM} \mathrm{H}_{2} \mathrm{O}_{2}$ were best bound. The cell-surface ligands recognized by macrophages were suggested to be sialylpolylactosaminyl sugar chains of a major sialoglycoprotein CD43 because 1) the cell binding was inhibited by oligosaccharides containing sialylpolylactosaminyl chains, and their inhibitory activity was destroyed by a polylactosamine-cleaving enzyme endo- $\beta$-galactosidase, and by neuraminidase; 2 ) the oxidized Jurkat cells pretreated with either glycosidase or with anti-CD43 antibody were not bound. The macrophage receptor involved in the binding was suggested to be cell-surface nucleolin because 1) anti-nucleolin antibody inhibited the binding; 2) nucleolin-transfected HEK293 cells bound the oxidized cells; and 3) this binding was inhibited by antinucleolin antibody and by anti-CD43 antibody. CD43 on oxidized Jurkat cells tended to form clusters in good accordance with their susceptibility to the macrophage binding. CD43 clustering and the oxidized-cell binding to macrophages were prevented by a caspase inhibitor Z-VAD-fmk, suggesting that the oxidized and bound cells were undergoing apoptosis. Indeed, caspase-3 activity of Jurkat cells increased by the oxidation. These results suggest that moderately oxidized cells undergo apoptosis and are recognized by macrophages as early apoptotic cells.

Key words phagocytosis; oxidative stress; apoptosis; macrophage; nucleolin; CD43

Oxidative stress is known to cause various damages to cellular components such as nucleic acids, lipids, and proteins. $^{1-3)}$ The damages to the cellular components are induced by free radical reactions including degradation, adduct formation, cross-linking, bond-breaking reactions, and so forth. ${ }^{1-3)}$ Therefore oxidatively stressed cells are thought to undergo cell-membrane damages including membrane protein denaturation and cross-linking by free radicals.

We previously studied the responses of macrophages to oxidatively damaged cells such as oxidized erythrocytes, ${ }^{4,5)}$ neutrophils, ${ }^{6}$ and Jurkat T cells, ${ }^{7)}$ using various oxidants, and found that macrophages recognize and remove these oxidatively damaged cells. ${ }^{4}{ }^{-7}$ The determinants on the oxidized cell surface that macrophages recognize were not chemically modified nor denatured membrane structure, but were preexisting carbohydrate chains containing sialyl residues and polylactosaminoglycan structures, possibly sialylpoly- $N$-acetyllactosaminyl chains, of membrane glycoproteins. ${ }^{4-7)}$ Then, a question how macrophages discriminate the preexisting cellsurface carbohydrate chains of oxidized cells from those of unoxidized cells arose, and this was explained by the hypothesis that membrane glycoproteins aggregate to form clusters upon cell oxidation, presumably due to free radical-mediated protein cross-linking, and the resultant clusters of their extracellular polylactosaminoglycans provide multivalent and therefore high-affinity ligands for macrophage receptors. ${ }^{4-8)}$ However, there was no conclusive evidence for the membrane glycoprotein aggregation on oxidatively damaged cells ${ }^{9-12)}$ and for the presence of the putative macrophage receptors. ${ }^{13-15)}$

In another series of recent works on apoptotic cells, we found that $\mathrm{CD} 43$, a major membrane sialoglycoprotein of hematopoietic cells containing sialyl residues and poly- $N$ acetyllactosaminyl chains, of Jurkat cells aggregates to form clusters and caps at an early stage of apoptosis, and the early apoptotic Jurkat cells were recognized and taken up by macrophages through the clustered and capped CD43. ${ }^{16)}$ CD43 is a heavily sialylated membrane glycoprotein, ${ }^{17)}$ and the determinants on CD43 glycoprotein of early apoptotic cells were suggested to be sialylpoly- $N$-acetyllactosaminyl sugar chains ${ }^{16)}$ similarly to the determinants on oxidized cells for the macrophage recognition described above. In addition, we identified the macrophage receptor for sialylpoly- $N$ acetyllactosaminyl chains as nucleolin, ${ }^{18)}$ a multifunctional shuttle protein present in nucleus and cytoplasm and on the surface of some types of cells including macrophages, ${ }^{19,20)}$ and demonstrated that nucleolin expressed on cell surface recognizes early apoptotic cells but not non-apoptotic cells. ${ }^{18)}$ We also demonstrated that phosphatidylserine (PS), a wellinvestigated cell-surface marker for apoptotic cells, ${ }^{21-23)}$ is not exposed on the cell surface at the early stage of apoptosis, but is at relatively later stages. ${ }^{24)}$

Considering the similarity between the sugar chain ligands on oxidatively damaged cells and those on early apoptotic cells for macrophage recognition, and that oxidative stress is one of the factors that can induce apoptosis, ${ }^{25-28)}$ it is conceivable that the oxidatively damaged cells that we have so far investigated are also early apoptotic cells, and that they are recognized by macrophages as early apoptotic cells.

To answer this question, we carried out the present study, focusing on the following points: 1) oxidation conditions optimum for macrophage binding; 2) dependency on CD43 and on sialylpoly- $N$-acetyllactosaminyl sugar chains in the binding; 3) involvement of macrophage surface nucleolin in the 
binding; 4) CD43 clustering at the optimum oxidation conditions; 5) dependency on caspases in CD43 clustering and in the macrophage binding; and 6) other apoptosis-associated nuclear, cytosolic, and cell-surface changes.

\section{MATERIALS AND METHODS}

Cells Jurkat, THP-1, and HEK293 cells were obtained from Riken Cell Bank, Tsukuba, Japan, Japanese Cancer Research Resources Bank, Osaka, Japan, and Health Science Research Resources Bank, Osaka, Japan, respectively. THP-1 macrophages were obtained by treatment of THP-1 cells with phorbol myristate acetate as previously described. ${ }^{16)}$

Materials Hydrogen peroxide $\left(\mathrm{H}_{2} \mathrm{O}_{2}\right)$, bisbenzimide (Hoechst 33258), and trypsin (E.C. 3.4.21.4, porcine pancreas) were purchased from Wako Pure Chemical Industries (Osaka, Japan). PKH26 (red) and PKH67 (green) fluorescent cell linker kit, bovine serum albumin (BSA), and phorbol myristate acetate were obtained from Sigma-Aldrich. Benzyloxycarbonyl-Val-Ala-Asp(OMe) fluoromethyl ketone (ZVAD-fmk) was the product of Peptide Institute (Osaka, Japan). Endo- $\beta$-galactosidase (E.C. 3.2.1.103, Escherichia freundii) was obtained from Seikagaku Fine Chemicals (Tokyo, Japan). Neuraminidase (E.C. 3.2.1.18, Vibrio cholelae) was purchased from Behringwerke AG (Marburg, Germany). Anti-CD43 mouse monoclonal antibody (clone DFT1), control mouse IgG1, and control rabbit IgG were obtained from DAKO (Glostrup, Denmark). Alexa Fluor-488 goat anti-mouse IgG1 $(\mathrm{H}+\mathrm{L})$ conjugate was the product of Molecular Probe (Eugene, U.S.A.). NucView ${ }^{\mathrm{TM}} 488$ Caspase-3 substrate for live cells was obtained from Biotium (Hayward, U.S.A.). MEBCYTO apoptosis kit was purchased from Medical and Biological Laboratories (Nagoya, Japan). Antibody against a synthetic octapeptide corresponding to the residues 295-302 of nucleolin (anti-NUC295) was raised in rabbits and affinity purified similarly to in work previously described. ${ }^{18)}$ Oligosaccharides of human erythrocyte membrane glycoprotein, mainly those from band 3 glycoprotein, were prepared by hydrazinolysis of defatted human erythrocyte ghosts as described previously. ${ }^{5}$ )

Oxidation of Jurkat Cells Oxidation of Jurkat cells was carried out by incubation of the cells $\left(1 \times 10^{7}\right.$ cells $\left./ \mathrm{ml}\right)$ in Hank's balanced salt solution (HBSS) with appropriate concentrations of $\mathrm{H}_{2} \mathrm{O}_{2}$ at $37^{\circ} \mathrm{C}$ with gentle shaking.

Binding and Phagocytosis Assays THP-1 cells were differentiated into macrophages by phorbol myristate acetate as described previously. ${ }^{16)}$ Macrophages on coverslips were washed in Dulbecco's phosphate-buffered saline (DPBS) free of $\mathrm{Ca}^{2+}$ and $\mathrm{Mg}^{2+}$ (DPBS(-)) before use. Jurkat cells $(1 \times$ $10^{7}$ cells $/ \mathrm{ml}$ ) treated with $\mathrm{H}_{2} \mathrm{O}_{2}$ were washed three times with DPBS(-), resuspended in RPMI 1640 medium bufferized with $20 \mathrm{~mm}$ HEPES, pH 7.2 (RPMI1640-HEPES) at $4 \times 10^{6}$ cells $/ \mathrm{ml}$, and coincubated with macrophage monolayers on coverslips at $37^{\circ} \mathrm{C}$ for $2 \mathrm{~h}$ with gentle shaking. Unbound cells were removed by gentle washing, then bound Jurkat cells and macrophages were fixed with $1.25 \%$ glutaraldehyde and stained with Mayer's hematoxylin solution. The number of bound Jurkat cells and macrophages was counted under a light microscope $(\times 400$ magnification). The data are expressed as the number of bound Jurkat cells/100 macrophages as counting $>200$ macrophages. For phagocytosis assay, $\mathrm{H}_{2} \mathrm{O}_{2}$ - treated Jurkat cells were labeled with PKH67 green fluorescent cell linker kit according to the manufacturer's instruction. The labeled Jurkat cells were coincubated with macrophage monolayers for 2 or $4 \mathrm{~h}$. After coincubation, unbound and lightly attached Jurkat cells were removed by washing and by treatment with $0.5 \mathrm{mg} / \mathrm{ml}$ trypsin at room temperature for $2 \mathrm{~min}$. Then the cell membrane was stained with PKH26 red fluorescent cell linker kit, and Jurkat cells taken up by macrophages were identified under a confocal laser scanning fluorescence microscope ( $\mu$-Radiance; BioRad).

Binding Assay Using Human Nucleolin-Expressing HEK293 Cells Human nucleolin cDNA was transfected into monolayers of HEK293 cells (HEK cells) (Health Science Research Bank, Osaka, Japan) as described previously. ${ }^{18)} \mathrm{H}_{2} \mathrm{O}_{2}$-oxidized Jurkat cells were applied to the monolayer of HEK cells after additional 1-h incubation to adjust the time of oxidation to that of macrophage assays, and co-incubated at $37^{\circ} \mathrm{C}$ for $1 \mathrm{~h}$ with gentle shaking. After removal of unbound cells, attached cells were fixed, stained and counted as described above. All the data are expressed as the number of bound Jurkat cells per 100 HEK cells (cell binding) as counting $>200$ cells.

Measurement of Cell-Surface CD43 Jurkat cells were treated with $10 \mu \mathrm{g} / \mathrm{ml}$ anti-CD43 mouse monoclonal antibody (clone DF-T1 ${ }^{29}$ ) in RPMI 1640-HEPES with $0.2 \%$ BSA at $0{ }^{\circ} \mathrm{C}$ for $30 \mathrm{~min}$ and washed several times with $\operatorname{DPBS}(-)$ at $0^{\circ} \mathrm{C}$. Bound antibody was detected by treatment of the cells with $10 \mu \mathrm{g} / \mathrm{ml}$ Alexa Fluoro-488 goat anti-mouse $\operatorname{IgG}(\mathrm{H}+\mathrm{L})$ conjugate in RPMI 1640-HEPES with $0.2 \%$ BSA at $0{ }^{\circ} \mathrm{C}$ for $30 \mathrm{~min}$ and washing several times with $\operatorname{DPBS}(-)$ at $0{ }^{\circ} \mathrm{C}$. The cells were resuspended in RPMI 1640-HEPES without phenol red at $0{ }^{\circ} \mathrm{C}$ and immediately subjected to microscopic observation by a confocal laser scanning fluorescence microscope. Throughout the immunofluorescence staining process, the cell suspensions were kept at $0{ }^{\circ} \mathrm{C}$ to prevent antibody-induced antigen redistribution that may occur at higher temperatures.

Measurement of Apoptosis Apoptosis of the $\mathrm{H}_{2} \mathrm{O}_{2}$ treated cells was assessed by caspase- 3 activation, chromatin condensation, and PS externalization. Caspase-3 activity was measured by the fluorescence intensity of the fluorogenic DNA dye released from the dye-DEVD substrate by activated caspase-3, using a commercial assay kit NucView $^{\mathrm{TM}}$ 488 Caspase-3 Assay Kit for Live cells). Briefly, Jurkat cells $\left(2 \times 10^{5}\right.$ cells) were suspended in RPMI-HEPES (without phenol red) containing appropriate concentrations of the substrate, and incubated at room temperature for $30 \mathrm{~min}$ in the dark according to the manufacturer's instruction. The cell suspension was diluted with another buffer and immediately analyzed by a flow cytometer (FACSCalibur, Becton-Dickinson) using a software CELLQUEST, gating for FSC and SSC region of intact Jurkat cells. For measurement of chromatin condensation, $\mathrm{H}_{2} \mathrm{O}_{2}$-treated Jurkat cells were fixed with $1.25 \%$ glutaraldehyde in $\operatorname{DPBS}(-)$ at room temperature for $30 \mathrm{~min}$ followed by staining with $0.1 \mathrm{~mm}$ bisbenzimide (Hoechst 33258 ) in DPBS $(-)$ at $4{ }^{\circ} \mathrm{C}$ overnight. Morphology of the nuclei of Jurkat cells was observed under a fluorescence microscope. Externalization of PS was assessed by binding of fluorescein isothiocyanate-labeled annexin $\mathrm{V}$ (FITC-annexin V) to the cells using a commercial assay kit 
(MEBCYTO apoptosis kit). Briefly, Jurkat cells $\left(2 \times 10^{5}\right.$ cells) suspended in a kit buffer containing appropriate concentrations of FITC-annexin $\mathrm{V}$ and propidium iodide were incubated at room temperature for $15 \mathrm{~min}$ in the dark according to the manufacturer's instruction. The cell suspension was then diluted with another buffer and immediately subjected to flow cytometric analysis (FACSCalibur, BectonDickinson) gating for FSC and SSC region of intact Jurkat cells. Propidium iodide-positive cells were regarded as necrotic cells.

Statistical Analysis The data are presented as the mean \pm S.D. of at least triplicate experiments. The data were compared by Student's $t$ test, and statistical significance was determined. $* p<0.05 ; * * p<0.01$; and $* * * p<0.001$.

\section{RESULTS}

Phagocytic Recognition of $\mathrm{H}_{2} \mathrm{O}_{2}$-Oxidized Jurkat Cells by Macrophages At first, conditions for oxidation of target cells suitable for macrophage binding assay were examined using Jurkat T cells as target cells and human monocytic THP1 cells differentiated into adherent cells as macrophages. Jurkat cells were incubated with various concentrations of $\mathrm{H}_{2} \mathrm{O}_{2}$ at $37^{\circ} \mathrm{C}$ for $1 \mathrm{~h}$, and subjected to the macrophage binding assay. As shown in Fig. 1A, Jurkat cells oxidized with $0.1 \mathrm{~mm} \mathrm{H}_{2} \mathrm{O}_{2}$ were best bound by macrophages, and the susceptibility of the cells to macrophage binding gradually de- clined as the concentration of $\mathrm{H}_{2} \mathrm{O}_{2}$ increased. Therefore we hereafter used Jurkat cells oxidized with $0.1 \mathrm{~mm} \mathrm{H}_{2} \mathrm{O}_{2}$ for $1 \mathrm{~h}$ unless otherwise indicated.

To see whether the observed binding of oxidized Jurkat cells by macrophages is followed by phagocytosis, oxidized Jurkat cells were labeled with a green fluorescent dye, and the labeled Jurkat cells were co-incubated with macrophages for 2 or $4 \mathrm{~h}$. After co-incubation, unbound and lightly attached Jurkat cells were removed, and the cell membrane was stained with a red fluorescent dye, then the cells were observed under a confocal laser scanning fluorescence microscope. As shown in Fig. 1B right, the number of oxidized cells ingested by macrophages did not increase at $2 \mathrm{~h}$, and significantly increased at $4 \mathrm{~h}$, as compared with unoxidized cells, while binding of the oxidized cells to macrophages did not change (Fig. 1B left). Thus phagocytosis of the oxidized cells appears to take $>2 \mathrm{~h}$. Figure $1 \mathrm{C}$ shows confocal images of the oxidized Jurkat cells bound and ingested by macrophages. These observations indicate that the oxidized cells are to be phagocytosed by macrophages.

Involvement of Sialylpolylactosaminyl Chains of CD43 in the Recognition In previous studies, sialylpolylactosaminyl chains of oxidized-cell surface were suggested to be recognized by macrophages. ${ }^{4-7)}$ To confirm this using $\mathrm{H}_{2} \mathrm{O}_{2}$-oxidized Jurkat cells, and to see the involvement of CD43 as a sialylpolylactosaminyl chain-containing glycoprotein, inhibition studies were performed. As shown in Fig. 2A,
A

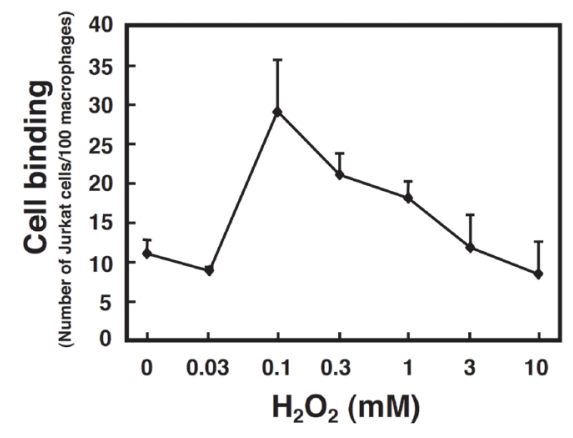

C
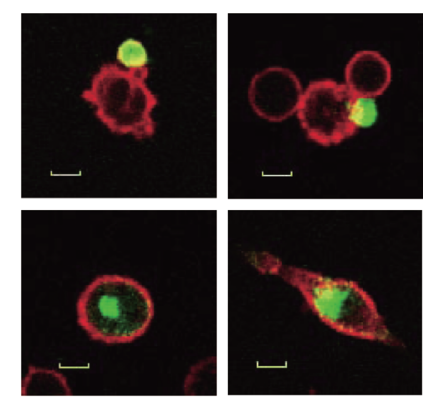

bar: $10 \mu \mathrm{m}$

B
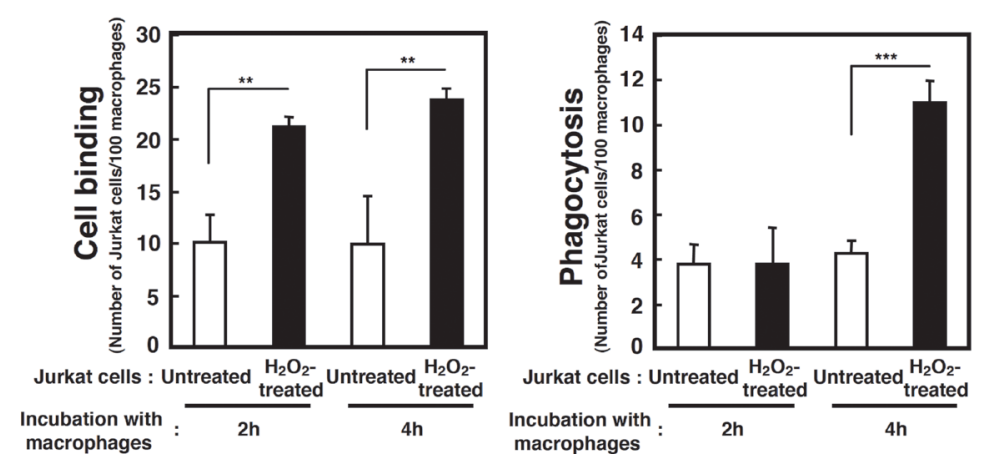

Fig. 1. Phagocytic Recognition of Oxidized Jurkat Cells by Macrophages

(A) Susceptibility of Jurkat cells to macrophage binding as a function of the concentration of $\mathrm{H}_{2} \mathrm{O}_{2}$-treatment. Jurkat cells were incubated with the indicated concentrations of $\mathrm{H}_{2} \mathrm{O}_{2}$ in $\mathrm{HBSS}$ at $37^{\circ} \mathrm{C}$ for $1 \mathrm{~h}$, and subjected to the binding assay as described in Materials and Methods. Each point represents the mean \pm S.D. of triplicate experiments. (B) Time dependency in phagocytosis. Jurkat cells were incubated with or without $0.1 \mathrm{~mm}_{2} \mathrm{O}_{2}$ for $1 \mathrm{~h}$, and subjected to binding (left panel) and phagocytosis (right panel) assays, where Jurkat cells and macrophages were co-incubated for 2 and $4 \mathrm{~h}$. The assays were performed as described in Materials and Methods. Each column represents the mean \pm S.D. of triplicate experiments. (C) Confocal images of oxidized Jurkat cells bound and ingested by macrophages. Jurkat cells treated with $0.1 \mathrm{~mm} \mathrm{H}_{2} \mathrm{O}_{2}$ for $1 \mathrm{~h}$ were subjected to the $4-\mathrm{h}$ phagocytosis assay. (Green cells) Jurkat cells. (Red area) Macrophage cell membrane. (Yellow area) Area of oxidized Jurkat cells attaching to macrophages. (Upper left panel) Tightly bound Jurkat cell on macrophage. (Upper right panel) Jurkat cell being ingested by macrophage. (Lower panels) Ingested Jurkat cells within macrophages. 
an oligosaccharide preparation from human erythrocyte membrane inhibited the binding of $\mathrm{H}_{2} \mathrm{O}_{2}$-oxidized Jurkat cells to macrophages. The inhibitory activity of the oligosaccharides was destroyed by endo- $\beta$-galactosidase that specifically cleaves poly- $N$-acetyllactosaminyl structure (i.e., (Gal $\beta 1$ -

\section{A}

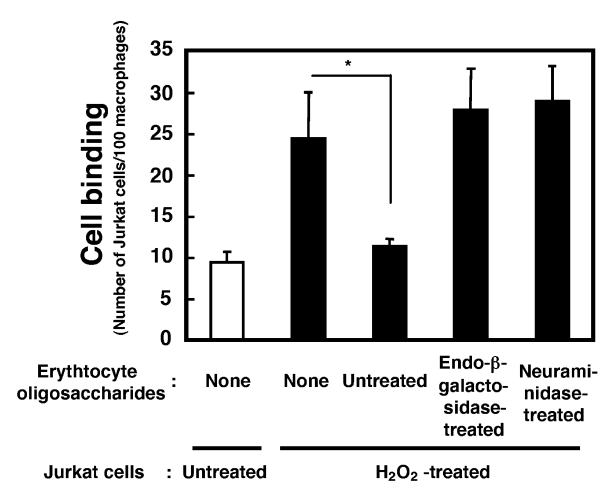

$\mathbf{B}$
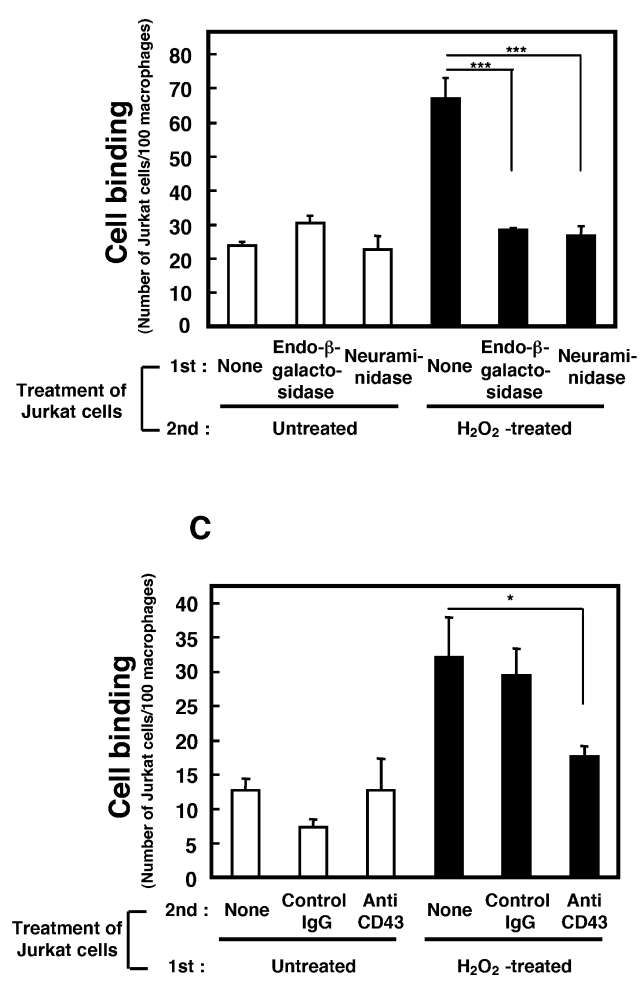

Fig. 2. Involvement of Sialylpolylactosaminyl Chains of CD43 on Oxidized Jurkat Cells in their Binding to Macrophages

Jurkat cells were oxidized with $0.1 \mathrm{~mm} \mathrm{H}_{2} \mathrm{O}_{2}$ in HBSS at $37^{\circ} \mathrm{C}$ for $1 \mathrm{~h}$, and subjected to the binding assay as described in Materials and Methods. Each column represents the mean \pm S.D. of triplicate experiments. (A) Inhibition of binding of oxidized Jurkat cells to macrophages by oligosaccharides from erythrocyte membrane. Binding of oxidized Jurkat cells to macrophages was carried out in the presence or the absence of oligosaccharides $(100 \mu \mathrm{g} / \mathrm{ml})$ prepared from human erythrocyte membrane, or those digested with endo- $\beta$-galactosidase $(0.1$ units $/ \mathrm{ml})$ or neuraminidase $(0.1$ uinits $/ \mathrm{ml})$ in $50 \mathrm{~mm} \mathrm{ac}$ etate buffer ( $\mathrm{pH} 5.8$ ) $-0.1 \mathrm{M} \mathrm{NaCl}$ at $37^{\circ} \mathrm{C}$ for $48 \mathrm{~h}$ followed by heat inactivation $\left(100{ }^{\circ} \mathrm{C}, 2 \mathrm{~min}\right)$ of the enzymes. (B) Loss of binding of oxidized Jurkat cells to macrophages by pretreatment of Jurkat cells with glycosidases. Jurkat cells were incubated with endo- $\beta$-galactosidase $(0.1$ units $/ \mathrm{ml})$ or neuraminidase $(0.1$ units $/ \mathrm{ml})$ in RPMI1640-HEPES at $37^{\circ} \mathrm{C}$ for $1 \mathrm{~h}$, washed, oxidized with $\mathrm{H}_{2} \mathrm{O}_{2}$, and subjected to the binding assay with macrophages as described under in Materials and Methods. (C) Inhibition of binding of oxidized Jurkat cells to macrophages by anti-CD43 antibody. Oxidized Jurkat cells were incubated with or without $10 \mu \mathrm{g} / \mathrm{ml}$ of anti-CD43 mouse monoclonal antibody (clone DF-T1) or control mouse IgG1 in RPMI1640-HEPES containing $0.2 \% \mathrm{BSA}$ at $0{ }^{\circ} \mathrm{C}$ for $30 \mathrm{~min}$, washed, and subjected to binding assay with macrophages.
$4 \mathrm{GlcNAc} \beta 1-3)$ repeats) at the $\beta$-galactosidic bond, ${ }^{30)}$ or with neuraminidase that removes sialic acid from the non-reducing termini of the chains. In addition, Jurkat cells pretreated with endo- $\beta$-galactosidase or neuraminidase prior to $\mathrm{H}_{2} \mathrm{O}_{2}$ oxidation did not bind to macrophages (Fig. 2B). These results suggest that sialylpolylactosaminyl chains are involved in the binding to macrophages. The binding of $\mathrm{H}_{2} \mathrm{O}_{2}$-oxidized Jurkat cells was inhibited by anti-CD43 monoclonal antibody (clone: DF-T1), an antibody directed against a sialic acid-dependent unidentified epitope of CD43 ${ }^{29}$ (Fig. $2 \mathrm{C}$ ). Therefore it is likely that $\mathrm{H}_{2} \mathrm{O}_{2}$-oxidized Jurkat cells are recognized by macrophages through the sialylpolylactosaminyl chains of CD43.

Involvement of Macrophage-Surface Nucleolin in Recognition of Oxidized Jurkat Cells Whether the macrophage receptor for the oxidized Jurkat cells is nucleolin, a recently identified macrophage receptor for early apoptotic cells, ${ }^{18)}$ was examined. As shown in Fig. 3A, macrophage binding to $\mathrm{H}_{2} \mathrm{O}_{2}$-oxidized Jurkat cells was significantly inhibited by anti-nucleolin antibody (anti-NUC295, an antibody against the amino acid residues of nucleolin 295-302), while control rabbit $\mathrm{IgG}$ was ineffective, suggesting that macrophage surface nucleolin is involved in the binding of $\mathrm{H}_{2} \mathrm{O}_{2}$-oxidized Jurkat cells.

To confirm directly the ability of cell-surface nucleolin to bind the oxidized cells, recombinant nucleolin was expressed on the surface of non-macrophage cells HEK, and their ability to bind the oxidized cells was tested. Nucleolin-expression vector constructed in pcDNA4 was transiently transfected into HEK cells as described previously. ${ }^{18)}$ Sixteen hours after transfection, at which expression of nucleolin was confirmed, ${ }^{18)}$ binding of $\mathrm{H}_{2} \mathrm{O}_{2}$-oxidized and unoxidized Jurkat cells to the nucleolin-transfected HEK cells was tested. As shown in Fig. 3B, nucleolin-transfected HEK cells bound the oxidized cells significantly more than untransfected HEK cells. This binding of $\mathrm{H}_{2} \mathrm{O}_{2}$-oxidized cells was inhibited by anti-NUC295, but not by control IgG (Fig. 3C). These results suggest that cell surface-expressed nucleolin recognizes the oxidized Jurkat cells.

As shown in Fig. 3D, binding of $\mathrm{H}_{2} \mathrm{O}_{2}$-oxidized Jurkat cells to the nucleolin-transfected HEK cells was inhibited by anti-CD43 antibody but not by control $\mathrm{IgG}$, which confirmed that nucleolin binds to CD43 of the oxidized cells.

CD43 Forms Clusters on Oxidized Jurkat Cells Distribution of CD43 on $\mathrm{H}_{2} \mathrm{O}_{2}$-oxidized Jurkat cells was observed by immunofluorescence microscopy using anti-CD43 antibody. As shown in Fig. 4B, cells oxidized with $0.1 \mathrm{~mm}$ $\mathrm{H}_{2} \mathrm{O}_{2}$ for $1 \mathrm{~h}$ and incubated for an additional $2 \mathrm{~h}$ to adjust the incubation time to that of the macrophage-binding assay, contained cells bearing clustered CD43, while unoxidized control cells did less so (Fig. 4A). The extent of the induction of CD43 clustering was dependent upon the $\mathrm{H}_{2} \mathrm{O}_{2}$ concentrations used (Fig. 4C), and this concentration-dependent profile is very similar to that of macrophage binding shown in Fig. 1A. This coincidence suggests that macrophages bind to oxidized cells through CD43 clusters. The amount of CD43 on Jurkat cell surface did not change by oxidation with $\mathrm{H}_{2} \mathrm{O}_{2}$ at concentrations $\leq 1 \mathrm{~mm}$ as assessed by flow cytometry (data not shown). Therefore the observed lower macrophage binding of Jurkat cells oxidized with $\mathrm{H}_{2} \mathrm{O}_{2}$ at 0.3 and $1 \mathrm{~mm}$ in Fig. $1 \mathrm{~A}$ is not due to a decrease in the amount of CD43 but likely 
A

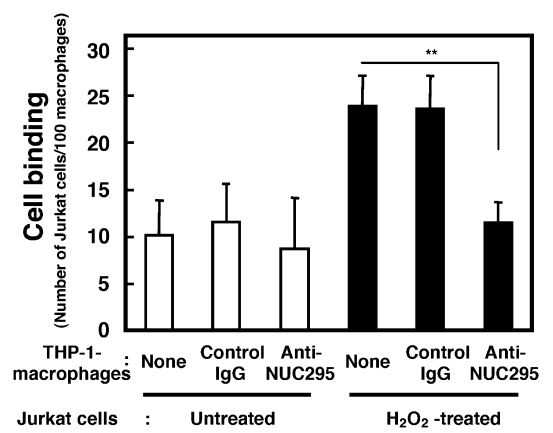

B

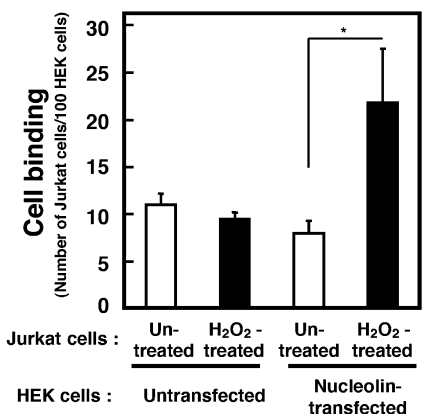

C

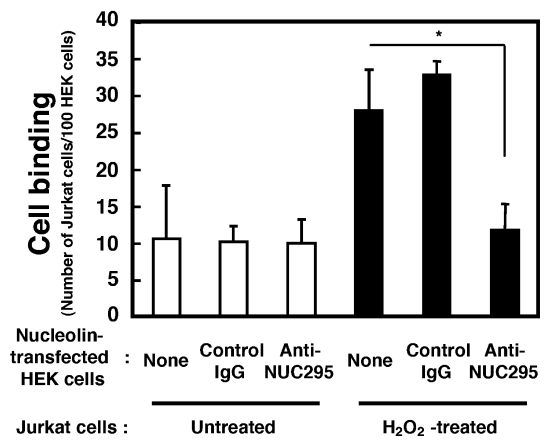

D

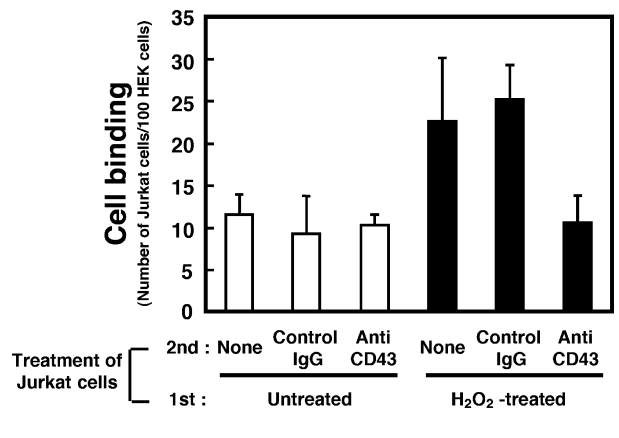

Fig. 3. Involvement of Macrophage-Surface Nucleolin in Recognition of Oxidized Jurkat Cells by Macrophages

Jurkat cells were oxidized with $0.1 \mathrm{mM} \mathrm{H}_{2} \mathrm{O}_{2}$ in HBSS at $37^{\circ} \mathrm{C}$ for $1 \mathrm{~h}$. Each column represents the mean \pm S.D. of triplicate experiments. (A) Inhibition of the binding of oxidized Jurkat cells to macrophages by anti-NUC295 antibody. Macrophages were preincubated with $2 \mu \mathrm{g} / \mathrm{ml}$ anti-NUC295 or control rabbit IgG in RPMI1640-HEPES containing $0.2 \% \mathrm{BSA}$ at $4{ }^{\circ} \mathrm{C}$ for $30 \mathrm{~min}$, washed, and subjected to binding assay using oxidized cells. (B) Binding of oxidized Jurkat cells to nucleolin-transfected HEK cells. HEK cells were transiently transfected with nucleolin as described in Materials and Methods, and subjected to binding assay using oxidized cells. (C) Inhibition of binding of oxidized Jurkat cells to nucleolin-transfected HEK cells by anti-NUC295 antibody. HEK cells transiently transfected with nucleolin as described in Materials and Methods were preincubated with $2 \mu \mathrm{g} / \mathrm{ml}$ anti-NUC295 or control rabbit IgG in RPMI1640-HEPES containing $0.2 \%$ BSA at $4{ }^{\circ} \mathrm{C}$ for 30 min, washed, and subjected to binding assay using oxidized cells. (D) Inhibition of binding of oxidized Jurkat cells to nucleolin-transfected HEK cells by anti-CD43 antibody. Oxidized Jurkat cells were treated with anti-CD43 mouse monoclonal antibody or control mouse IgG1 as described in the legend to Fig. 2C, washed, and subjected to binding assay with nucleolin-transfected HEK cells.

A

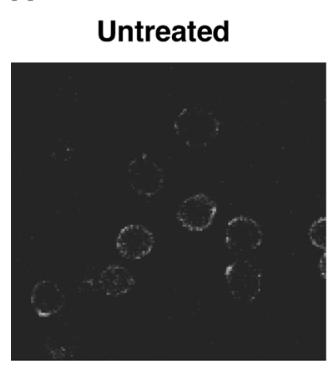

$0.1 \mathrm{mM} \mathrm{H}_{2} \mathrm{O}_{2}$-treated

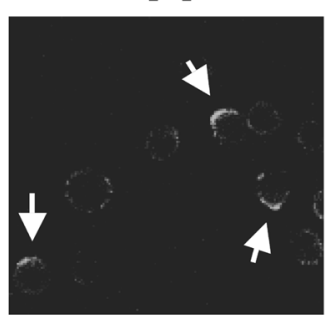

C

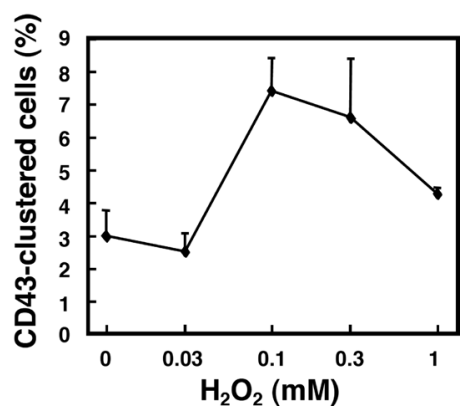

Fig. 4. Clustering of CD43 on Oxidized Jurkat Cells

Distribution of CD43 on Jurkat cells was observed by immunofluorescence microscopy as described in Materials and Methods, using anti-CD43 mouse monoclonal antibody (clone: DF-T1) as primary antibody, and Alexa Fluor-488 goat anti-mouse IgG as secondary antibody. Throughout the immunostaining procedures the cells were kept at $0{ }^{\circ} \mathrm{C}$. (A, B) CD43 distribution on unoxidized and oxidized Jurkat cells, respectively. Jurkat cells were incubated without or with $0.1 \mathrm{~mm} \mathrm{H}_{2} \mathrm{O}_{2}$ in $\mathrm{HBSS}$ at $37^{\circ} \mathrm{C}$ for $1 \mathrm{~h}$. The cells were washed and incubated again in RPMI1640-HEPES in the absence of $\mathrm{H}_{2} \mathrm{O}_{2}$ at $37^{\circ} \mathrm{C}$ for an additional $2 \mathrm{~h}$ to adjust the incubation time to that of macrophage-binding assay. Arrows, CD43-clustered cells. (C) The optimal concentration of $\mathrm{H}_{2} \mathrm{O}_{2}$ for $\mathrm{CD} 43$ clustering. Jurkat cells were oxidized with the indicated concentrations of $\mathrm{H}_{2} \mathrm{O}_{2}$ in $\mathrm{HBSS}$ at $37^{\circ} \mathrm{C}$ for $1 \mathrm{~h}$, processed as described in the legend to A and B, and the number of the cells showing CD43 clustering was counted. Each point represents the mean \pm S.D. of triplicate determinations.

to the lower levels of CD43-clustered cells.

Involvement of Caspase Activity in CD43 Clustering and in Susceptibility of Oxidized Jurkat Cells to Macrophage Recognition To see whether the observed CD43 clustering and the susceptibility to macrophage recog- nition of $\mathrm{H}_{2} \mathrm{O}_{2}$-oxidized Jurkat cells are caused by apoptotic processes, the effect of Z-VAD-fmk, a pan-caspase inhibitor, ${ }^{31)}$ was tested. As shown in Fig. 5, preincubation of Jurkat cells with Z-VAD-fmk prevented the $\mathrm{H}_{2} \mathrm{O}_{2}$-induced CD43 clustering (A) and macrophage recognition (B) of the 
A

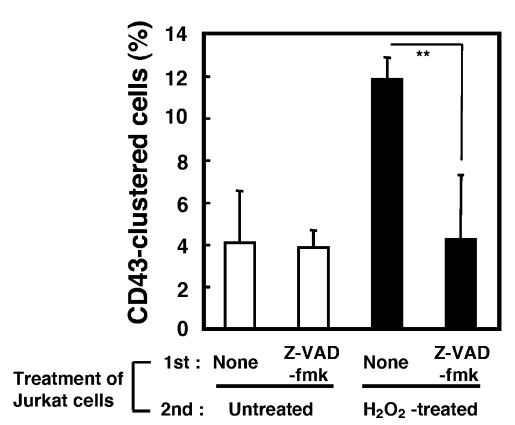

B

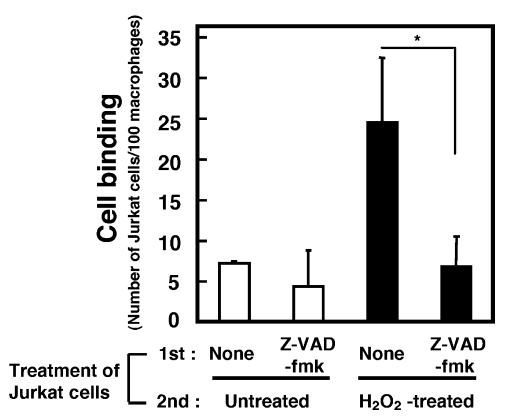

Fig. 5. Involvement of Caspases in CD43 Clustering and Macrophage Recognition of Oxidized Jurkat Cells

Jurkat cells were incubated in RPMI 1640 -HEPES at $37^{\circ} \mathrm{C}$ for $1 \mathrm{~h}$ in the absence or presence of $10 \mu \mathrm{M} \mathrm{Z-VAD-fmk}$. The cells were washed in HBSS, and oxidized with $0.1 \mathrm{~mm}$ $\mathrm{H}_{2} \mathrm{O}_{2}$ in $\mathrm{HBSS}$ at $37^{\circ} \mathrm{C}$ for $1 \mathrm{~h}$. After washing in HBSS, the cells were incubated again in RPMI1640-HEPES in the absence of $\mathrm{H}_{2} \mathrm{O}_{2}$ at $37^{\circ} \mathrm{C}$ for an additional $2 \mathrm{~h}$ to adjust the incubation time to that of macrophage-binding assay. (A) Effect of Z-VAD-fmk on CD43 clustering on $\mathrm{H}_{2} \mathrm{O}_{2}$-oxidized Jurkat cells. Each column represents the mean \pm S.D. of triplicate experiments. (B) Effect of Z-VAD-fmk on susceptibility of $\mathrm{H}_{2} \mathrm{O}_{2}$-oxidized Jurkat cells to macrophage recognition. Each column represents the mean \pm S.D. of triplicate experiments.

cells to the levels of control cells. These results suggest that caspases and thus apoptotic processes are involved in CD43 clustering and increased susceptibility of the oxidized cells to macrophage recognition.

Apoptosis-Associated Changes of Oxidized Jurkat Cells We further measured whether apoptosis is occurring in the $\mathrm{H}_{2} \mathrm{O}_{2}$-oxidized Jurkat cells. Jurkat cells were treated with $0-10 \mathrm{mM} \mathrm{H}_{2} \mathrm{O}_{2}$ for $1 \mathrm{~h}$, washed, incubated for an additional $2 \mathrm{~h}$ without $\mathrm{H}_{2} \mathrm{O}_{2}$ to adjust to the conditions for the macrophage-binding assay as was done in Fig. 1A, and subjected to measurement of caspase-3 activation, chromatin condensation, and PS exposure. As shown in Fig. 6A, cytosolic caspase-3 was activated during the 1- $\mathrm{h}_{2} \mathrm{O}_{2}$ incubation and the additional 2-h incubation without $\mathrm{H}_{2} \mathrm{O}_{2}$, depending on the $\mathrm{H}_{2} \mathrm{O}_{2}$ concentrations. Chromatin condensation did not occur during 1-h $\mathrm{H}_{2} \mathrm{O}_{2}$ oxidation (Fig. $6 \mathrm{~B}$, open circles), but some proportions of the cells underwent chromatin condensation in the additional 2-h incubation period with a peak at $0.1 \mathrm{~mm} \mathrm{H}_{2} \mathrm{O}_{2}$ (Fig. 6B, closed circles). The latter profile is very similar to those of macrophage binding (Fig. 1A) and CD43 clustering (Fig. 4C). This again suggests that the observed CD43 clustering and macrophage binding of the oxidized cells are closely related to apoptosis.

PS exposure is a well-known signal for clearance of apoptotic cells by macrophages and is also used as a marker of apoptosis. Then, using FITC-annexin V as a probe, PS exposure was measured in cells oxidized for $1 \mathrm{~h}$ and incubated for an additional $2 \mathrm{~h}$. As shown in Fig. 6C, PS-exposed cells did not increase by oxidation until at $3 \mathrm{mM} \mathrm{H}_{2} \mathrm{O}_{2}$. Therefore PS exposure is unlikely involved in the observed concentrationdependent CD43 clustering and macrophage binding.

Requirement of Higher Concentrations of $\mathrm{H}_{2} \mathrm{O}_{2}$ and Longer Time after Oxidation for PS Exposure To see the conditions inducing PS exposure by $\mathrm{H}_{2} \mathrm{O}_{2}$, Jurkat cells oxidized with $0,0.1$, and $1 \mathrm{~mm}$ of $\mathrm{H}_{2} \mathrm{O}_{2}$ for $1 \mathrm{~h}$ were washed and cultured again for $\leq 24 \mathrm{~h}$ in medium containing serum. Percentages of PS-exposed cells or/and necrotic cells were measured by flow cytometry periodically after $\mathrm{H}_{2} \mathrm{O}_{2}$ oxidation. As shown in Fig. 7A, cells oxidized with $0.1 \mathrm{mM} \mathrm{H}_{2} \mathrm{O}_{2}$ for $1 \mathrm{~h}$ (closed squares) exposed PS slightly more than control cells (open circles) until $12 \mathrm{~h}$. Cells oxidized with $1 \mathrm{~mm}$ $\mathrm{H}_{2} \mathrm{O}_{2}$ for $1 \mathrm{~h}$ (closed triangles) exposed PS much more than control cells (open circles) until $24 \mathrm{~h}$. When the data shown in Fig. 7A are separately shown as non-necrotic (Fig. 7B) and necrotic (Fig. 7C) cells, there is no difference in the numbers of PS-exposed non-necrotic cells (Fig. 7B) between non-oxidized control cells (Fig. 7B, open circles) and $0.1 \mathrm{~mm}$ $\mathrm{H}_{2} \mathrm{O}_{2}$-oxidized cells (closed squares). However, oxidation with $1 \mathrm{mM} \mathrm{H}_{2} \mathrm{O}_{2}$ for $1 \mathrm{~h}$ significantly increased the number of PS-exposed non-necrotic cells at $4 \mathrm{~h}$ and thereafter (Fig. 7B, closed triangles). The results suggest that in $1-\mathrm{h}$ oxidative stress by $\mathrm{H}_{2} \mathrm{O}_{2}$, a relatively high concentrations of $\mathrm{H}_{2} \mathrm{O}_{2}$ such as $1 \mathrm{~mm}$ is required to induce PS exposure without necrosis, and the PS exposure occurs at $\geq 4 \mathrm{~h}$ later hours.

Considering that CD43 clustering was induced by $0.1 \mathrm{~mm}$ $\mathrm{H}_{2} \mathrm{O}_{2}$ at $3 \mathrm{~h}$ (Fig. $4 \mathrm{C}$ ), induction of PS exposure requires relatively higher concentrations of $\mathrm{H}_{2} \mathrm{O}_{2}$ and longer time.

\section{DISCUSSION}

In the present study, we have clarified that oxidatively damaged Jurkat cells that have been shown to be recognized by macrophages through their surface sugar chains ${ }^{7}$ are recognized by macrophages not as chemically denatured cells but as apoptotic cells at an early stage. We performed the present work focusing on the following three aspects: 1) the ligand molecules on the oxidized cells; 2) the receptor molecules on macrophage surfaces; and 3) involvement of caspases in generation of ligands on the oxidized cells.

The ligands on oxidized Jurkat cells recognized by macrophages have been suggested to be sialylpolylactosaminyl chains, but it was not known what glycoconjugate molecules carry those types of sugar chains and form clusters. The present study suggests that the sugar chains on $\mathrm{H}_{2} \mathrm{O}_{2}$-oxidized Jurkat cells recognized by macrophages are those of CD43, and CD43 actually forms clusters. Moreover, CD43 clustering and the cell susceptibility to macrophage binding showed quite similar dependencies on $\mathrm{H}_{2} \mathrm{O}_{2}$-concentration, suggesting that $\mathrm{CD} 43$ clustering induces macrophage binding and clearance of oxidized cells.

This is, however, not a sole possible mechanism. Another possibility that the sugar-chain ligands are formed on the oxidized Jurkat cell surface by combination of sialyl and polylactosaminyl residues of various surface-molecules in- 
A

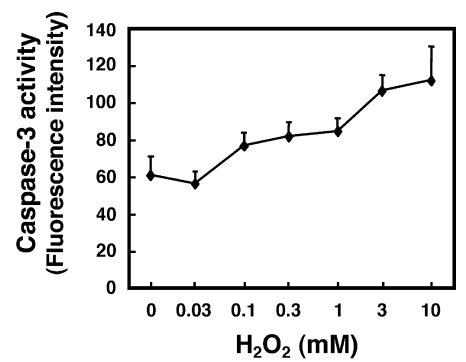

B

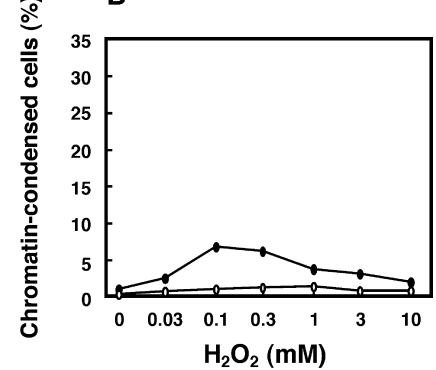

C

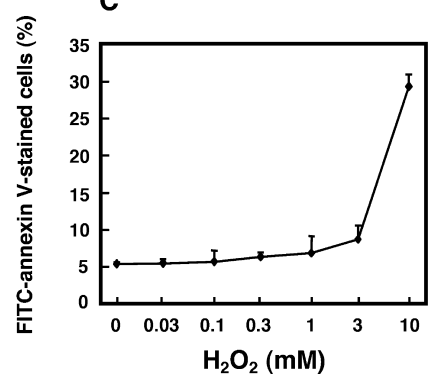

Fig. 6. Apoptosis-Associated Changes of Oxidized Jurkat Cells

Jurkat cells were incubated with the indicated concentrations of $\mathrm{H}_{2} \mathrm{O}_{2}$ in $\mathrm{HBSS}$ at $37^{\circ} \mathrm{C}$ for $1 \mathrm{~h}$. The cells were washed and incubated again in RPMI1640-HEPES in the absence of $\mathrm{H}_{2} \mathrm{O}_{2}$ at $37^{\circ} \mathrm{C}$ for an additional $2 \mathrm{~h}$ to adjust the incubation time to that of macrophage-binding assay, and subjected to measurement of apoptosis-associated cytosolic, nuclear, and cell-surface changes of the oxidized cells (closed circles). In the case of nuclear change measurement, changes at the end of 1-h incubation with $\mathrm{H}_{2} \mathrm{O}_{2}$ were also observed (open circles). The data for $\mathrm{B}$ and $\mathrm{C}$ are expressed in $\%$ of total cells. (A) Measurement of cytosolic caspase-3 activity. Caspase-3 activity was measured using NucView ${ }^{\mathrm{TM}} 488$ caspase- 3 substrate for live cells as described in Materials and Methods. Caspase- 3 activity is represented by the total fluorescense intensity (arbitrary units) of the fluorescent dye released from the substrate by the enzyme. Each point represents the mean \pm S.D. of triplicate experiments. (B) Measurement of chromatin-condensed cells. Chromatin condensation was measured using Hoechst 33258 dye as described in Materials and Methods. Open circle, chromatin-condensed cells at the end of 1-h exposure to $\mathrm{H}_{2} \mathrm{O}_{2}$. Closed circle, chromatin-condensed cells at the end of additional 2-h incubation in the absence of $\mathrm{H}_{2} \mathrm{O}_{2}$. Each point represents the mean of duplicate experiments. (C) Measurement of PS-exposed cells. Cells exposing PS were measured using FITC-annexin V as described in Materials and Methods. Each point represents the mean \pm S.D. of triplicate experiments. cluding CD43 is also conceivable. This possibility has not been studied because of its complexity.

The macrophage receptor recognizing the sialylpolylactosaminyl chains of CD43 clusters was characterized to be cell-surface nucleolin, as was the case for the early apoptotic cells. ${ }^{18)}$ In addition, CD43 clustering and the resultant susceptibility to macrophage binding were demonstrated dependent on caspase activities. These results indicate that macrophages recognize the $\mathrm{H}_{2} \mathrm{O}_{2}$-oxidized Jurkat cells as early apoptotic cells.

So far, various apoptosis-inducing agents, including etoposide, ${ }^{16,24)}$ anti-Fas antibody, ${ }^{16,24)}$ cycloheximide, ${ }^{16)}$ and thapsigargin (Ozawa and Beppu, unpublished observation) have been shown to induce CD43 clustering on early apoptotic Jurkat cells, and to lead them to phagocytic clearance by macrophage surface nucleolin. The present study showed that oxidative stress works as another apoptosis-inducing stress.

Polylactosaminyl sugar chains were found to be ligands for the macrophage binding of oxidatively damaged erythrocytes or senescent erythrocytes, ${ }^{4,5,8)}$ and we recently found that the macrophage receptor for $\mathrm{H}_{2} \mathrm{O}_{2}$-oxidized erythrocytes is nucleolin. ${ }^{32)}$ Interestingly, the optimal concentration of $\mathrm{H}_{2} \mathrm{O}_{2}$ is $0.1 \mathrm{~mm}$, and caspase inhibitors prevented erythrocyte change from unsusceptible to susceptible to macrophage recognition after oxidation, ${ }^{32}$ which suggests that caspases present in erythrocyte cytosol ${ }^{33)}$ play a role in the "eat-me signal" generation, possibly clustering of band 3 glycoprotein. This observation also supports the present results that moderately oxidized Jurkat cells undergo apoptosis, and as a result of caspase-dependent proteolysis of cytoplasmic or/and membrane proteins, CD43 clustering may be induced.

In the present study, oxidation of Jurkat cells with various concentrations of $\mathrm{H}_{2} \mathrm{O}_{2}$ resulted in an increase in caspase- 3 activity. This increased as the concentration of $\mathrm{H}_{2} \mathrm{O}_{2}$ increased (Fig. 6A). However, caspase-dependent CD43 clustering declined at $\mathrm{H}_{2} \mathrm{O}_{2}$ concentrations $>0.1 \mathrm{~mm}$ (Fig. 4C), which coincided with the profile of macrophage binding of $\mathrm{H}_{2} \mathrm{O}_{2}$-oxidized Jurkat cells (Fig. 1A). Similar biphasic binding profiles were previously observed in macrophage binding of etoposide- or anti-Fas antibody-induced early apoptotic cells. ${ }^{16)}$ The mechanism by which CD43 clustering declines is not known, but one possibility is that CD43 begins degrading at an early stage of apoptosis. ${ }^{16,24)}$ At high concentrations of $\mathrm{H}_{2} \mathrm{O}_{2}, \mathrm{CD} 43$ may degrade rapidly.

It should be noted that the $\mathrm{H}_{2} \mathrm{O}_{2}$ concentration-dependent rate of occurrence of CD43-clustered cells (Fig. 4C) coin-
A

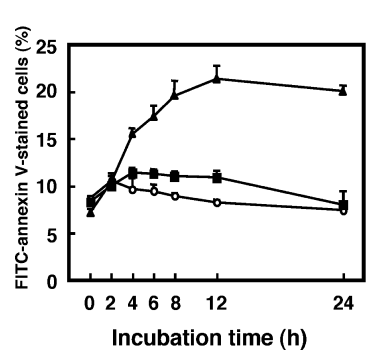

B

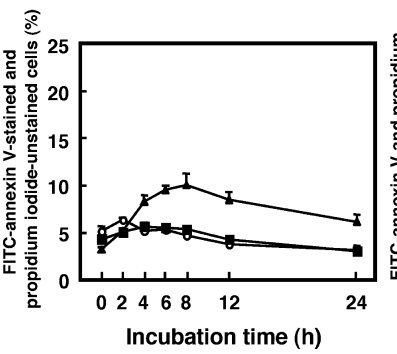

C

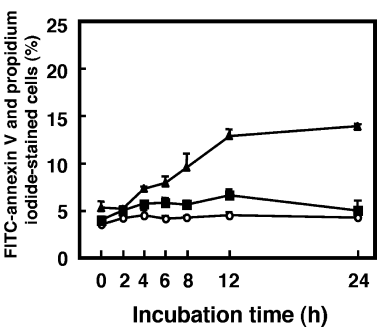

Fig. 7. Time-Course of PS Exposure on Oxidized Jurkat Cells

Jurkat cells were incubated with or without 0.1 and $1 \mathrm{~mm} \mathrm{H}_{2} \mathrm{O}_{2}$ in $\mathrm{HBSS}$ at $37^{\circ} \mathrm{C}$ for $1 \mathrm{~h}$. The cells were washed and incubated again in RPMI1640 medium containing $5 \%$ FBS in the absence of $\mathrm{H}_{2} \mathrm{O}_{2}$ at $37^{\circ} \mathrm{C}$ for the indicated times, and subjected to measurement of PS-exposed cells and necrotic cells using FITC-annexin $\mathrm{V}$ and propidium iodide, respectively, as described in Materials and Methods. Each point represents the mean \pm S.D. of triplicate experiments. (A) PS-exposed cells. (B) PS-exposed non-necrotic cells. (C) PSexposed necrotic cells. Open circles, cells incubated without $\mathrm{H}_{2} \mathrm{O}_{2}$. Closed squares, cells incubated with $0.1 \mathrm{~mm}_{2} \mathrm{O}_{2}$. Closed triangles, cells incubated with 1 mm $\mathrm{H}_{2} \mathrm{O}_{2}$. 
cided well with that of chromatin-condensed cells (Fig. 6B). Moreover, these changes occurred at the same time after $\mathrm{H}_{2} \mathrm{O}_{2}$ oxidation. It is therefore likely that CD43 clustering and chromatin condensation occur in the same cell at the same time. Some relationship may underlie the two phenomena.

Nucleolin that was found to be involved in the recognition of $\mathrm{H}_{2} \mathrm{O}_{2}$-oxidized Jurkat cells in the present study has been isolated as a macrophage surface protein that binds sialylpolylactosaminyl sugar chains. ${ }^{4,15)}$ At that time, it was a candidate protein for macrophage receptor-recognizing oxidized cells, ${ }^{3,15)}$ but was not yet identified as nucleolin. A few years later, clustered sialylpolylactosaminyl sugar chains were found to be also the cell surface ligands of the cells at an early stage of apoptosis for macrophage recognition, ${ }^{16}$ ) and the sialylpolylactosamine-binding macrophage protein was identified as nucleolin. ${ }^{18)}$ Considering the present result that moderately oxidized Jurkat cells are recognized by macrophages as early apoptotic cells, macrophage nucleolin recognizes oxidized Jurkat cells not as oxidatively damaged cells but simply as early apoptotic cells.

Macrophage receptors involved in the recognition and clearance of oxidatively damaged cells were also investigated by another group. Sambrano and Steinberg ${ }^{34)}$ reported a 94 97-kDa mouse peritoneal macrophage membrane protein that binds oxidized low density lipoprotein as a candidate for the macrophage receptor for oxidatively damaged erythrocytes and for apoptotic thymocytes. This protein was identified by the same group as macrosialin, the mouse homologue of human CD68. ${ }^{35)}$ However, whether this protein plays a role on macrophage surface in the recognition of oxidatively damaged erythrocytes and apoptotic thymocytes remains uncertain. $^{35)}$ Terpstra et $a l^{36)}$ reported that peritoneal macrophages from scavenger receptor A (SR-A)-deficient mice showed $20-30 \%$ less ability to bind apoptotic thymocytes than wild-type mice but showed comparable ability to bind oxidatively damaged erythrocytes, suggesting that SR-A does not play a role in the recognition of oxidized erythrocytes. In addition, it was also demonstrated by in vivo experiments that oxidatively damaged erythrocytes were efficiently taken up by Kupffer cells of SR-AI-and II-deficient mice, suggesting that receptors other than SR-AI and II participate in clearance of oxidatively damaged cells. ${ }^{37}$ )

$\mathrm{H}_{2} \mathrm{O}_{2}$, used as an oxidative stress agent in the present study, is a ubiquitous and general oxidant in the environment and in the body. ${ }^{38)}$ It is generated in water, foods, and air. It is also physiologically and pathologically generated in the living body. $\mathrm{H}_{2} \mathrm{O}_{2}$ itself is poorly reactive, but it generates a toxic hydroxyl radical $(\cdot \mathrm{OH})$ by catalytic actions of trace $\mathrm{Fe}$ or $\mathrm{Cu}$ ions, and damages the cellular constituents. ${ }^{1,2,37)}$ It is a neutral amphiphilic molecule and therefore easily permeates cellular membranes. It should be noted that the highest concentrations of $\mathrm{H}_{2} \mathrm{O}_{2}$ occurring in the body are estimated to be an order of $0.1 \mathrm{~mm}$ at inflammatory lesions. ${ }^{38)}$ In the present study, we oxidized Jurkat cells using $0.03-10 \mathrm{~mm}_{2} \mathrm{O}_{2}$, and observed CD43 clustering and subsequent macrophage binding using the cells oxidized with $0.1 \mathrm{mM} \mathrm{H}_{2} \mathrm{O}_{2}$. Accordingly, our present observations, including CD43 clustering, sialylpolylactosaminyl sugar chain-mediated macrophage recognition, and apoptosis induction, should be of physiological significance.
In conclusion, the present study suggests that macrophage recognition and clearance of oxidatively damaged cells so far observed ${ }^{4-7,13-15)}$ are not due to recognition of oxidatively damaged and denatured cell-surface components, but to recognition of the membrane glycoprotein molecules that undergo clustering by oxidative stress-induced apoptosis.

Acknowledgements This work was supported in part by a Grant-in-Aid for Scientific Research from the Japan Society for the Promotion of Science, and by a grant for a "Hightech research center" project for private universities: matching fund subsidy from MEXT, Japan, 2007.

\section{REFERENCES}

1) Halliwel B., FASEB J., 1, 358-364 (1987).

2) Halliwel B., Gutteridge J. M. C., "Free Radicals in Biology and Medicine," 2nd ed., Clarendon Press, Oxford, 1989.

3) Stadtman E. R., Annu. Rev. Biochem., 62, 797-821 (1993).

4) Beppu M., Takahashi T., Kashiwada M., Masukawa S., Kikugawa K., Arch. Biochem. Biophys., 312, 189-197 (1994).

5) Beppu M., Eda S., Fujimaki M., Hishiyama E., Kikugawa K., Biol. Pharm. Bull., 19, 188-194 (1996).

6) Beppu M., Yokoyama N., Motohashi M., Kikugawa K., Biol. Pharm. Bull., 24, 19-26 (2001).

7) Beppu M., Ando K., Saeki M., Yokoyama N., Kikugawa K., Arch. Biochem. Biophys., 384, 368-374 (2000).

8) Beppu M., Ando K., Kikugawa K., Cell. Mol. Biol., 42, 1007-1024 (1996).

9) Beppu M., Mizukami A., Nagoya M., Kikugawa K., J. Biol. Chem., 265, 3226-3233 (1990).

10) Beppu M., Mizukami A., Ando K., Kikugawa K., J. Biol. Chem., 267, 14691-14696 (1992).

11) Ando K., Kikugawa K., Beppu M., J. Biol. Chem., 269, 19394-19398 (1994).

12) Ando K., Kikugawa K., Beppu M., Arch. Biochem. Biophys., 339, $250-257$ (1997).

13) Eda S., Kikugawa K., Beppu M., Free Radic. Res., 27, 23-30 (1997).

14) Eda S., Kikugawa K., Beppu M., Biol. Pharm. Bull., 20, 127-133 (1997).

15) Eda S., Beppu M., Yokoyama N., Kikugawa K., Arch. Biochem. Biophys., 385, 186-193 (2001).

16) Eda S., Yamanaka M., Beppu M., J. Biol. Chem., 279, 5967-5974 (2004).

17) Ostberg J. R., Barth R. K., Frelinger J. G., Immunol. Today, 19, 546550 (1998)

18) Hirano K., Miki Y., Hirai Y., Sato R., Itoh T., Hayashi A., Yamanaka M., Eda S., Beppu M., J. Biol. Chem., 280, 39284-39293 (2005).

19) Nigg E. A., Nature (London), 386, 779_787 (1997).

20) Ginisty H., Sicard H., Roger B., Bouvet P., J. Cell Sci., 112, 761-772 (1999).

21) Martin S. J., Reutelingsperger C. P. M., McGahon A. J., Rader J. A., van Schie R. C. A. A., LaFace D. M., Green D. R., J. Exp. Med., 182, 1545-1556 (1995).

22) Verhoven B., Schlegel R. A., Williamson P., J. Exp. Med., 182, 1597 1601 (1995).

23) Verhoven B., Krahling S., Schlegel R. A., Williamson P., Cell. Death Differ, 6, 262-270 (1999).

24) Yamanaka M., Eda S., Beppu M., Biochem. Biophys. Res. Commun., 328, 273-280 (2005).

25) Sandstrom P. A., Tebbey P. W., van Cleave S., Buttke T. M., J. Biol. Chem., 269, 798-801 (1994).

26) Forrest V. J., Kang T. H., McClain D. E., Robinson D. H., Ramakrishnan N., Free Radic. Biol. Med., 16, 675-684 (1994).

27) Greenlund L. J. S., Deckwerth T. L., Johnson E. M., Jr., Neuron, 14, $303-315$ (1995).

28) Lin K.-T., Xue J.-Y., Nomen M., Spur B., Wong P. Y.-K., J. Biol. Chem., 270, 16487-16490 (1995).

29) de Smet W., Walter H., van Hove L., Immunology, 79, 46-54 (1993).

30) Fukuda M. N., Fukuda M., Hakomori S., J. Biol. Chem., 254, 5458- 
5465 (1979).

31) Slee E. A., Zhu H., Chow S. C., MacFarlane M., Nicholson D. W., Cohen G. M., Biochem. J., 315, 21-24 (1996).

32) Miki Y., Tazawa T., Hirano K., Matsushima H., Kumamoto S., Hamasaki N., Yamaguchi T., Beppu M., Biochem. Biophys. Res. Commun., 363, 57-62 (2007).

33) Berg C. P., Engels I. H., Rothbart A., Lauber K., Lenz A., Schlosser S. F., Schulze-Osthoff K., Wesselborg S., Cell Death Differ, , 8, 11971206 (2001).

34) Sambrano G. R., Steinberg D., Proc. Natl. Acad. Sci. U.S.A., 92,
1396-1400 (1995).

35) Ramprasad M. P., Fischer W., Witztum J. L., Sambrano G. R., Quehenberger O., Steinberg D., Proc. Natl. Acad. Sci. U.S.A., 92, 9580-9584 (1995).

36) Terpstra V., Kondratenko N., Steinberg D., Proc. Natl. Acad. Sci. U.S.A., 94, 8127-8131 (1997).

37) Terpstra V., van Berkel T. J. C., Blood, 95, 2157-2163 (2000).

38) Halliwel B., Clement M. V., Long L. H., FEBS Lett., 486, 10-13 (2000). 